NO.10 Journal of Petroleum Research \& Studies ( JPR \& S)

\title{
Integration of NMR, Conventional Logs and Core Data to Improve Formation Evaluation of a Gas Reservoir in Kangan and Dalan Formation, Iran
}

\begin{abstract}
Ali Mohammad Bagheri; Mohammad Mohammadnia; Ghafor Karimi Research Institute of Petroleum Industry, Tehran, Iran
\end{abstract}

\section{Abstract}

Conventional log based reservoir characterization of a gas reservoir in the Kangan and Dalan formations have recently been improved by application of the nuclear magnetic resonance log (NMR).

Important reservoir properties such as permeability pore size distribution and capillary pressure curves can be estimated from NMR. These parameters are simulated directly in the laboratory on core samples recovered from the reservoir. Due to high cost associated with coring and some technical problems, few wells in any given field are cored.

The only problem of NMR measurements in gas reservoirs is that in gas-bearing zones, total NMR porosity read much less than actual porosity due to low hydrogen index of the gas. This problem was solved by integration of NMR porosity with conventional well logs such as density and sonic and compared with core porosity. Improved porosity calculation lead to better core independent permeability estimation on the wells logged with NMR.

NMR T2 distribution was calibrated with laboratory derived pore size distribution in 7 samples and a constant scaling factor was derived for each rock type to predict a pseudo pore size distribution from NMR. 


\section{NO.10 Journal of Petroleum Research \& Studies ( JPR \& S)}

Logarithmic mean of pore size distribution in 4 wells with NMR was integrated with conventional logs in an artificial neural network to predict a pseudo pore size distribution logarithmic mean (PPSDLM) in the wells without NMR.

PPSDLM and conventional well logs were involved to an electrofacies modeling to predict electrofacies in the reservoir for characterization of heterogeneity of the reservoir in $3 \mathrm{D}$ geological model. NMR permeability was also imported to the model as an associated log to predict facies base permeability.

To test the permeability prediction, estimated permeability was compared with core derived permeability on 2 cored wells to see how well, estimated permeability fitted the actual core permeability.

Keywords: NMR, DMR, Porosity, Density, Signal amplitude, $\mathrm{T}_{2}$ distribution, $\mathrm{T}_{1}$ Polarization

\section{1-Introduction}

Finding and producing oil and gas in an efficient manner, to the economic benefit, of a company requires a reservoir model to predict reservoir performance under different development scenarios, including supplemental recovery, and to aid in designing an appropriate reservoir management plan. Development of a realistic reservoir model needs to accurate geologic model prepared based on integrated reservoir characterization that can evaluate vertical and lateral variability of reservoir properties, estimate hydrocarbon pore volumes, or to simulate fluid flow for performance prediction.

The most important parameter resulting uncertainty in reservoir properties in gas reservoirs is that in gas-bearing zones, different logging tools such as density, neutron, sonic and NMR logs are affected by gas and read more or less porosities. 


\section{NO.10 Journal of Petroleum Research \& Studies ( JPR \& S)}

The potential of nuclear magnetic resonance (NMR) measurements to provide information on formation pore fluids and pore structure was first identified in the 1950s. The first NMR log was run in 1960 (Brown and Gamson, 1960) and measured the signal from protons processing in the Earth's magnetic field. Early NMR logging tools required the doping of the drilling mud with magnetite to kill the borehole signal. A prototype of the CMR tool was field tested in 1992 (Morris et al., 1993). The first commercial tool was introduced worldwide in 1994 (Morris et al., 1994) [1].

The recent introduction of total NMR porosity measurements into the well logging industry has provided many new formation evaluation techniques (Prammer et al., 1996; Freedman et al., 1997; Coates et al., 1997). A new NMR interpretation method for the evaluation of gas-bearing formations was proposed by Freedman (1997) and is referred to as the Density-Magnetic Resonance (DMR) method [2].

The DMR method combines petrophysical response equations for total CMR porosity (TCMR) and formation bulk density measurements to derive new equations for gas-corrected total formation porosity.

In this study first of all we used Freedman method to calculate DMR porosity and gas saturation and then reservoir properties were evaluated using corrected NMR porosity. The DMRP calculation method was applied in one of Iranian huge gas reservoir, which is recently logged with CMR tool. The field is located in south of Iran, as shown in figure (1) and is comprised of by Upper Permian Dalan and Lower Triassic Kangan carbonates. Core description and petrography of core samples indicate that Kangan and Upper Dalan formations are mainly composed of dolomite, anhydrite and limestone, together with thin shaly laminations in Kangan member. 
This reservoir is subdivided into four individual zones from K1 to K4.

The K1 reservoir units are characterized by the development of limestone and dolomitic beds with moderate reservoir characteristics. The main K2 reservoir interval is limestone dominated with well-developed mouldic porosity as the main pore type. This unit forms one of the main storage layers for the K2 reservoir. The majority of $\mathrm{K} 3$ reservoir is tight anhydritic dolomite with only minor porosity development. The main reservoir development occurred in $\mathrm{K} 4$, which is initially dominated by mouldic and interparticle porosity particularly in the dolomite interval, followed by limy grainstones with moldic porosity.

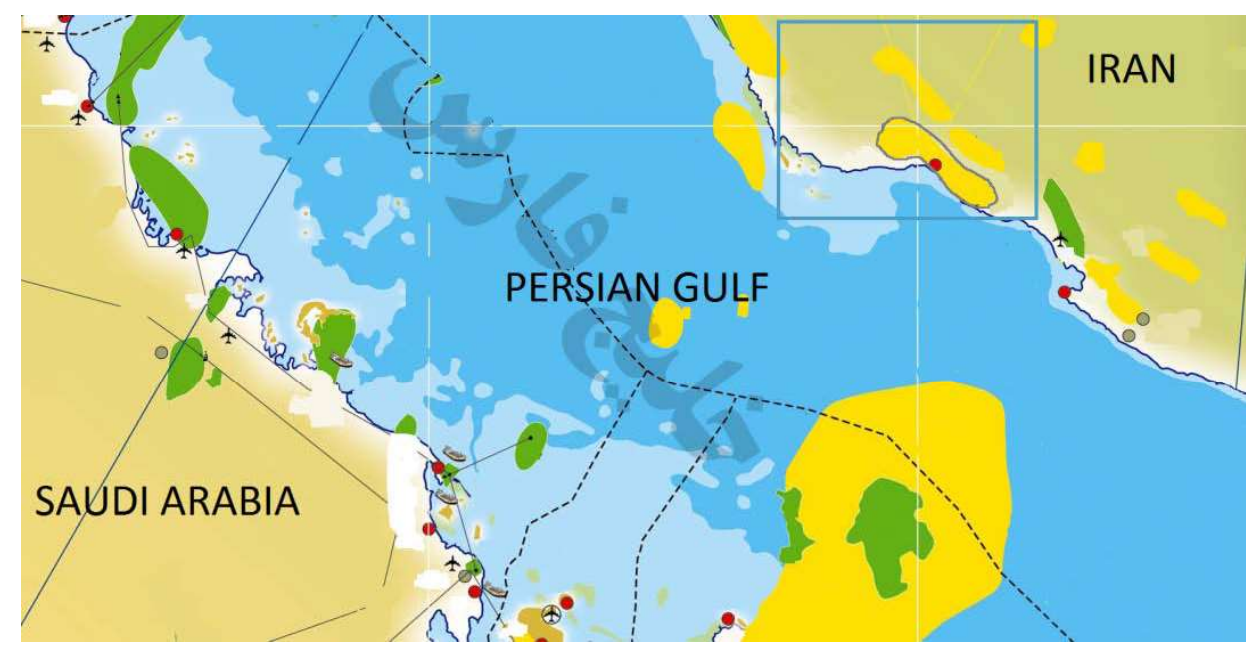

Fig. (1) Field Location Map

\section{$\underline{\text { 2- Combination of density and magnetic resonance porosity in gas reservoirs }}$}

In fluid filled rocks, the volume of rock occupied by fluid is equal to porosity. Petrophysical NMR measurements utilize hydrogen proton spins to generate a signal. Because hydrogen is abundant in fluids, the magnitude of the NMR signal is proportional to the formation fluid volume.

When all the proton spins are aligned in the magnetic field, the NMR signal is proportional to the porosity of the rock. 


\section{NO.10 Journal of Petroleum Research \& Studies ( JPR \& S)}

The signal is a multi exponent decay curve and can be mathematically defined in multiple decay time constants. The multiple decay time constants are smoothed to provide a $\mathrm{T} 2$ relaxation distribution curve figure (2). The area under the $\mathrm{T}_{2}$ curve is equal to the initial signal amplitude of the echo decay curve or porosity. Also T2 has been shown to be proportional to pore size [4].

The total CMR porosity $(T C M R)$ in gas-bearing formations is defined by:

$T C M R=\Phi S_{x o g}(H I)_{g} G P+\Phi\left(1-S_{x o g}\right)(H I)_{f}$

Where:

TCMR is NMR total porosity, $\Phi$ is total formation porosity, $S_{x o g}$ is flushed zone gas saturation, GP is gas polarization function, $(H I)_{g}$ is hydrogen index of gas and $(H I)_{f}$ is hydrogen index of fluid.
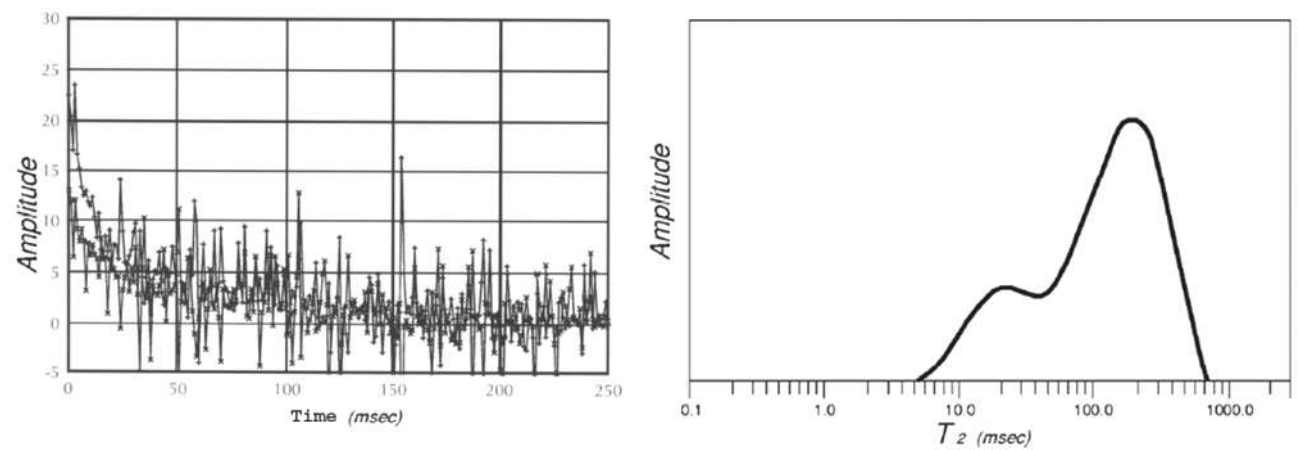

Fig. (2) Example of measured echo train (left) and resulting T2 distribution (right)

The problem of NMR measurements in gas reservoirs is that in Gas-bearing zones, total NMR porosities read much less than density-derived porosities.

Porosity derived from NMR is solely not sufficient in determine low hydrogen index of the gas and the long $\mathrm{T} 1$ polarization time of the gas when the data is acquired with insufficient wait time [2]. 


\section{NO.10 Journal of Petroleum Research \& Studies ( JPR \& S)}

Density magnetic resonance porosity (DMRP) can be calculated from combination of bulk density and TCMR using following equation proposed by Freedman [2].

$$
\Phi=\frac{\left(\frac{\rho_{b-} \rho_{m a}}{\rho_{f}-\rho_{m a}}\right) \times\left(1-\frac{(H I)_{g} \times G P}{(H I)_{f}}\right)+\frac{\left(\rho_{f}-\rho_{g}\right) \times T C M R}{\left(\rho_{m a}-\rho_{f}\right) \times(H I)_{f}}}{\left(1-\frac{(H I)_{g} \times G P}{(H I)_{f}}\right)+\frac{\left(\rho_{f}-\rho_{g}\right)}{\left(\rho_{m a}-\rho_{f}\right)}}
$$

Where $\Phi$ corrected formation porosity (DMRP) is, $\rho_{b}$ is bulk density, $\rho_{m a}$ is matrix density, $\rho_{f}$ is fluid density, $\rho_{g}$ is Gas density.

\section{3- Formation evaluation of the reservoir}

The DMRP calculation method is applied in one of Iranian huge gas reservoir, which is recently logged with CMR tool. The Kangan and Dalan formations in this reservoir in south of Iran are two of the most important reservoirs in the world. These formations are composed of limestone, dolomite, anhydrite and shale. This reservoir is subdivided into four individual zone and all four zones produce gas.

The heterogeneous carbonate reservoir has undergone post depositional diagenesis, which have had an impact on reservoir characteristics. Calcite cementation and dissolution, dolomitisation and particularly precipitation of anhydrite cements and shales have destroyed porosity and affect the permeability in the reservoir.

A number of 17 wells were selected for this study. Selected wells were drilled with water-base mud and penetrated a massive gas reservoir. Conventional cores were cut over the zones of interest on 5 wells and full set logs were carried out for all 17 wells. The CMR_Plus tool was logged at $270 \mathrm{~m} / \mathrm{hr}$ using a $2.1 \mathrm{sec}$ wait time in four wells. A petrophysical database was constructed that incorporates wire-line logs, NMR, core and layer data. 


\section{NO.10 Journal of Petroleum Research \& Studies ( JPR \& S)}

The gas-corrected porosity (DMRP) in the wells with NMR log provides an accurate formation total porosity that can be used to improve gas reserve estimates.

Figure (3) show the full set logs, $\mathrm{T}_{2}$ distribution of NMR and interpretation results in one of selected wells. A strong gas effect on the neutron and density logs is evident from the large separation between RHOB and NPHI as shown in track 4 .

NMR porosity (TCMR), Density porosity (PHIT_DEN) and DMRP logs are compared with core derived porosity in track 8. This comparison shows good match between calculated DMRP and core porosity. Also Track 9 shows that core permeability and NMR permeability are in good agreement.

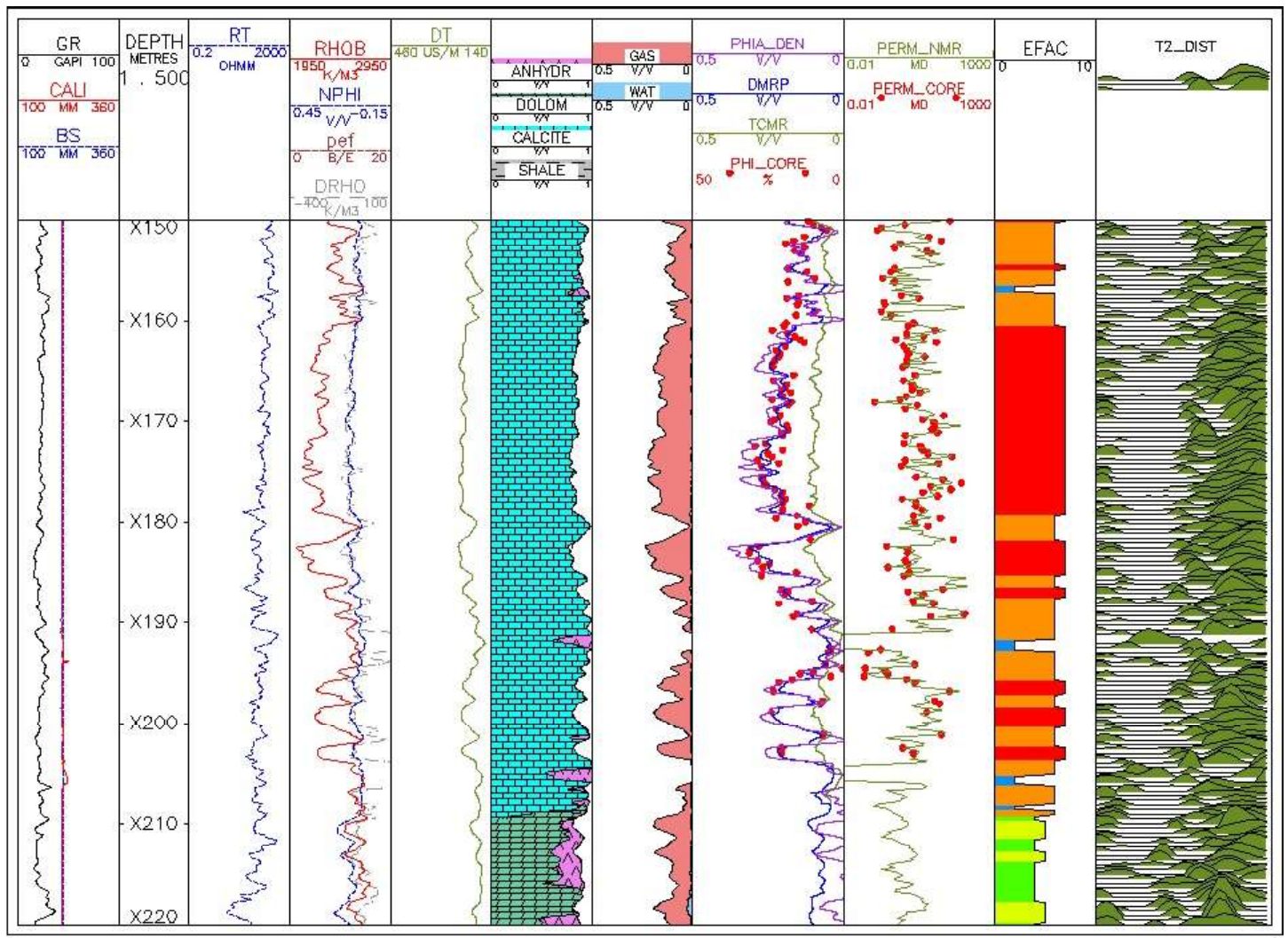

Fig. (3) Full set logs, $T_{2}$ distribution of NMR and interpretation results in gas zone of well 


\section{NO.10 Journal of Petroleum Research \& Studies ( JPR \& S)}

In addition to evaluation of porosity and permeability, combination of resulted porosity and permeability with log and core data helps define three dimensional reservoir facies models that describe the distribution of porosity, permeability and capillary pressure in more detail.

In this step, to include the effect of pore size in facies modeling, pseudo pore size distribution was predicted from NMR-T 2 distribution.

$\mathrm{T}_{2}$ distribution depends on the properties of the fluid and the poral structure. To remove the effect of fluid properties, $\mathrm{T}_{2}$ distribution was converted into single phase water saturated pseudo $T_{2}$ distribution, using an application kit included in the NMR processing module within Geolog software.

Hence we can assume that the NMR- $\mathrm{T}_{2}$ distribution of transverse relaxation times will be mainly governed by the surface relaxation mechanism, and that it will be directly proportional to the pore volume to surface ratio, and hence to the pore radius.

A scaling factor parameter $(\rho)$ needed to $T_{2}$ distribution is properly transformed into pore size distribution according to following equation.

With the core derived $T_{2}$ distribution in 7 water saturated sample which one of them is presented in figure (4) as an example, the scale factor parameter is simply adjusted until the T2 distribution matches the core Helium injection entry radios.

$$
\operatorname{PoreSize}(\mu m)=6 \rho \frac{T 2}{1000}
$$

Logarithmic mean of pore size distribution in 4 wells with NMR was integrated with conventional logs in a back propagation artificial neural network to predict a pseudo pore size distribution logarithmic mean (PPSDLM) in the wells without NMR. 
Logarithmic mean of pore size distribution from NMR was compared with pseudo pore size distribution logarithmic mean in track 9 of figure (5) for one of wells as an example.

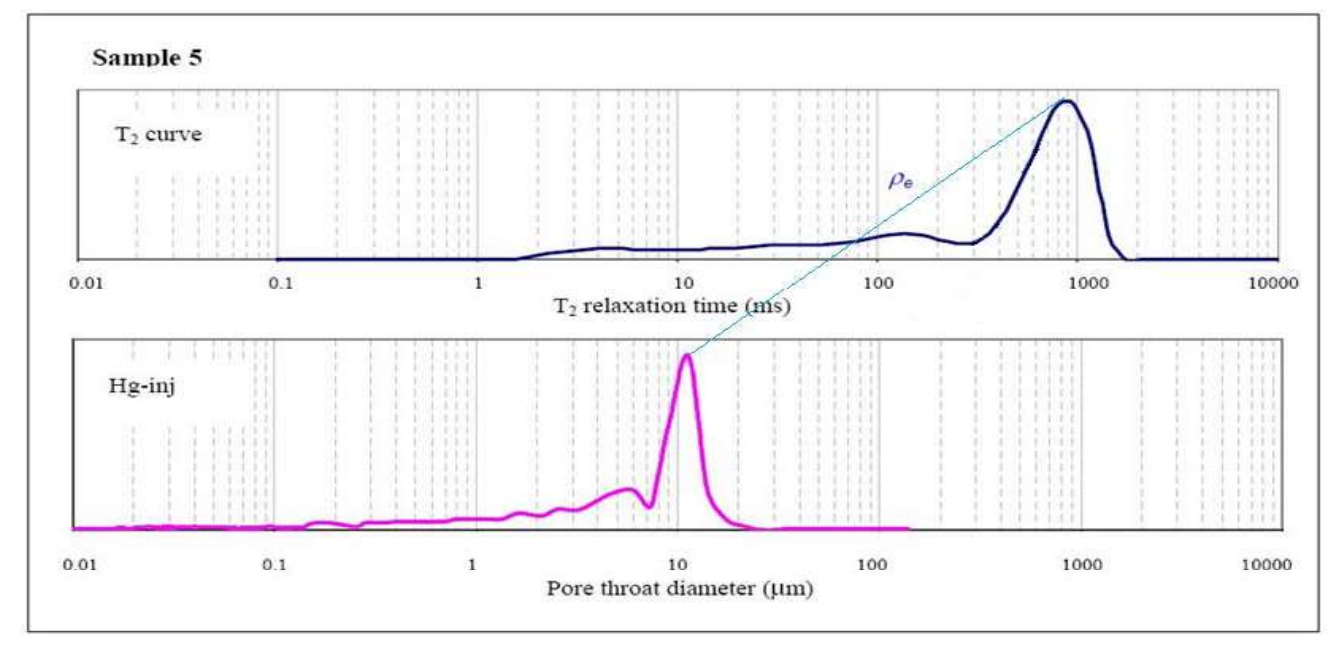

Fig. (4) $\mathrm{T}_{2}$ relaxation time versus pore throat diameter from $\mathrm{Hg}$-ing test and pore size relaxivity parameter, $\rho$

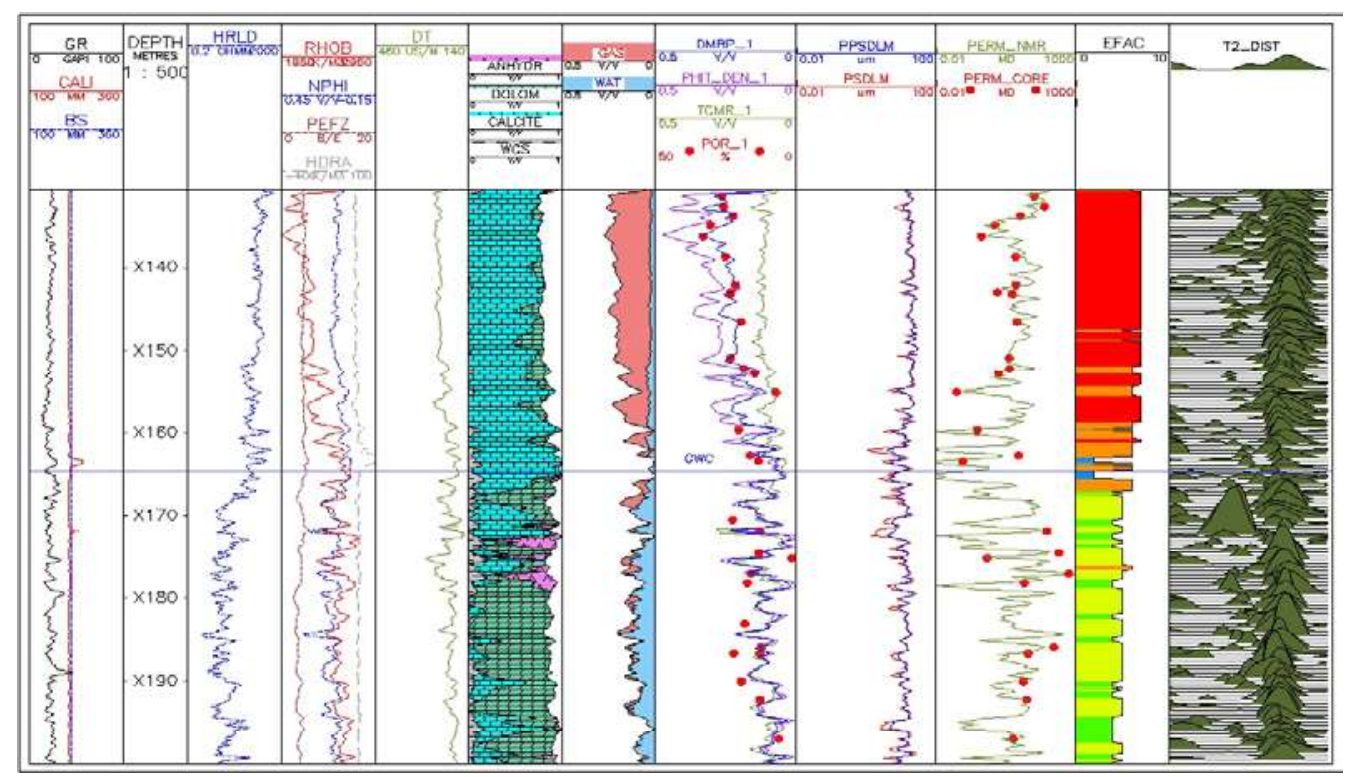

Fig. (5) Full set logs, $T_{2}$ distribution of NMR and interpretation results in gas and water zone of well B 


\section{NO.10 Journal of Petroleum Research \& Studies ( JPR \& S)}

An efficient way to perform a facies analysis is to setup a classification model that partitions the log data into sets of log responses that characterize facies and allow the facies to be distinguished from others. In a later stage of the survey, the model is propagated over the other wells of the same field.

In this study MRGC method (Multi-Resolution Graph-Based Clustering) was used to identify electrofacies in the wells.

PPSDLM and conventional well logs were involved to an electrofacies modeling (MRGC) to predict electrofacies in the reservoir for characterization of heterogeneity of the reservoir in 3D geological model.

Continuous NMR permeability was imported to the model as an associated log to predict permeability over the entire field simultaneously.

To test the permeability prediction, the techniques were calibrated in 2 NMR wells and blind tested in two cored wells to see how well estimated permeability fitted the actual core permeability.

As indicated in figure (6) A \& B, there is good match between NMR facies base predicted permeability and core measurements. Also presented histograms (C \& D) show that predicted permeability and NMR permeability in two predicted electrofacies in well A are in good agreement. A cross section of final electrofacies modeling of all 17 wells is presented in figure (7). This cross section shows that predicted electrofacies based on log data is a very good indicator of reservoir heterogeneity over the field. 

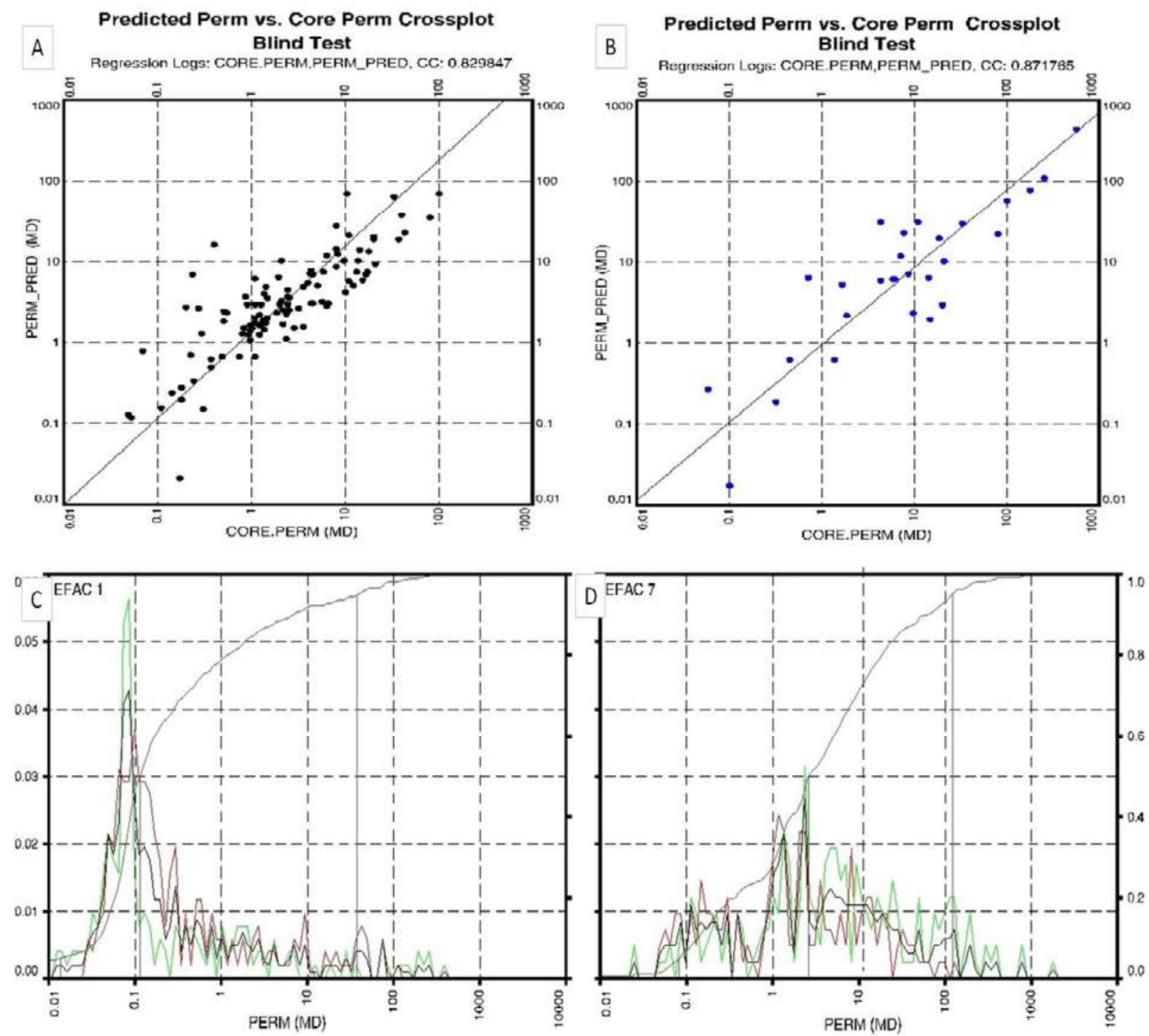

Fig. (6) A\& B: Comparison between predicted permeability and core measurements in two cored wells, C \& D: histograms comparison between NMR permeability and predicted permeability in two predicted electrofacies in well $\mathrm{A}$ 


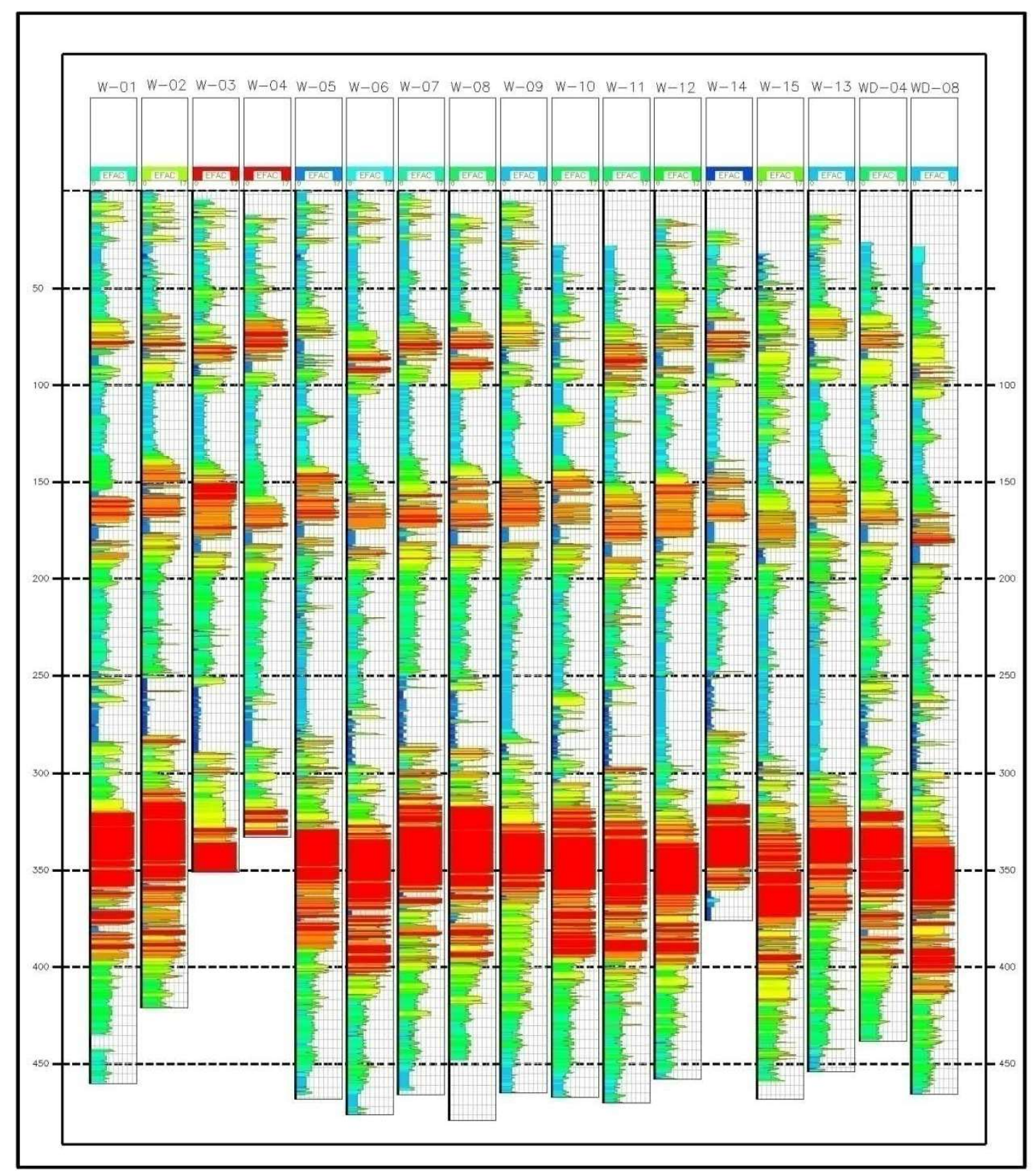

Fig. (7) Sample cross section of final electrofacies model in selected wells 


\section{Conclusions}

Combining density log and NMR measurements improves the petrophysical evaluation of gas-bearing formations giving the total porosity corrected for gas effect. The DMR technique is able to produce a very good porosity estimate comparable to that estimated from the density-neutron logs and to porosity measurements on conventional core. Improved porosity calculation should lead to better core independent permeability estimation on the wells logged with NMR.

$\mathrm{T}_{2}$ distribution of transverse relaxation times that appears in NMR logs, represents the distribution of the pore sizes and can be integrated with conventional logs in electrofacies modeling procedure to incorporate pore size distribution in addition to porosity.

Seventeen wells from the field were evaluated for electrofacies using MRGC method. A facies base continuous permeability curve was also estimated over the wells that can be used as a direct input to the geological models. Electrofacies can also use as a heterogeneity modeler when sound rock types and flow units are not available. 


\section{Reference}

1. McKeon D. (Schlumberger) et al.; "An Improved NMR Tool Design for Faster Logging”, SPWLA 40th Annual Logging Symposium, May 30-June 3, (1999).

2. Freedman R.(Schlumberger), "Gas-corrected porosity from density-Porosity and CMR measurements", in How to use borehole nuclear magnetic resonance", Schlumberger Oilfield Review, v. 9, no. 2, p. 54, (1997).

3. Juan Carlos Glorioso (Repsol YPF) et al.; " Deriving Capillary Pressure and Water Saturation from NMR Transversal Relaxation Times", SPE Latin American and Caribbean Petroleum Engineering Conference held in Port-ofSpain, Trinidad, West Indies, 27-30 April (SPE 81057), (2003).

4. George Coates et al., NMR logging principles and applications, Halliburton, (2001).

5. Chanh Cao Minh (SPE), et al., "Sonic-Magnetic Resonance Method: A Sourceless Porosity Evaluation in Gas-Bearing Reservoirs", 1999 SPE Annual Technical Conference and Exhibition held in Houston, Texas, 3-6 October (SPE 56767), (1999).

6. Benjamin D. Lowden, Matthew J. Porter and Linda S. Powrie: " $T_{2}$ Relaxation Time Versus Mercury Injection Capillary Pressure: Implications for NMR Logging and Resewoir Characterisation", from SPE European Petroleum Conference held in The Hague (Netherlands, 20-22 October 1998), SPE-50607

7. Howard J.J., Kenyon W.E., Straley C.; "Proton magnetic resonance and pore-size variations in reservoir sandstones", in SPE annual technical conference

8. Exhibition proceedings, SPE-20600, pages 733-742 (later published in 1993: SPE Formation Evaluation, v. 8, no. 3, p. 194-200), (1990). 
NO.10 Journal of Petroleum Research \& Studies ( JPR \& S)

9. Flaum C., Kleinberg R., Hurlimann M.; "Identification of gas with the Combinable Magnetic Resonance Tool (CMR)", paper L in 37th annual logging symposium transactions (SPWLA, 1996).

10. Juan Carlos Glorioso, Omar Aguirre, Gabriel Piotti (Repsol YPF) and JeanFrançois Mengual (Schlumberger); 'Deriving Capillary Pressure and Water Saturation from NMR Transversal Relaxation Times", SPE Latin American and Caribbean Petroleum Engineering Conference held in Port-of-Spain, Trinidad, West Indies, 27-30 April (2003). 